Smell and taste seemed to be normal, and the dynamometer registered 105 kilogrammes with each hand.

A consideration of the history and symptoms present in this case led to the conclusion that we had to deal with intra-cranial syphilis. Before his admission into the infirmary he had been under the care of half a dozen medical men in succession, and appears to have been treated for the most part by means of quinine and other anti-neuralgic remedies. His last medical adviser, however, evidently suspected the syphilitic nature of his complaint, and gave him iodide of potassium. He took it at first in doses of ten grains three times a day, but for a week before his admission the dose was increased to thirty grains. This had not the slightest effect upon the pain or other symptoms. Accordingly, on the $12 \mathrm{th}$ of February, he was ordered to rub into the skin daily one drachm of Shoemaker's mercurious oleate ointment, while thirty minims of paraldehyde were prescribed at night to procure sleep. In a few days the pain had completely disappeared, and up to the present date (April 1st) he has remained perfectly well. The mercurial treatment is, however, being continued as a precautionary measure. ${ }^{2}$

\section{WHY DOES SALICYLIC ACID CURE RHEUMATISM ?}

BY P. W. LATHAM, M.A., M.D., F.R.C.P.,

DOWNING PROFESSOR OF MEDICINE, CAMBRIDGE; SEMIOR PHYSICIAY TO ADDENBROOKE'S HOSPITAL.

(Concluded from p. 1121.)

IF, then, as I assert, uric acid or its antecedent is the materies morbi which develops rheumatic fever, and if, as I have previously advocated, it is according to the accepted opinion the cause of gout, why should it in some individuals produce this disorder and in others rheumatism?

Let us in the first place consider what, under the normal state of things, is the effect of cold and heat applied to the surface of the body. The effect, as you know, is very different as regards cold-blooded and warm-blooded animals. External cold diminishes and heat increases the metabolic activity of the cold-blooded animal, acting like a mixture of dead substances in a chemical retort. But in a warm-blooded animal, within certain limits, cold increases and heat diminishes the bodily metabolism, as shown by the increased or diminished consumption ef oxygen and production of carbonic acid as the temperature falls or rises. There is obviously a mechanism of some kind counteracting and indeed overcoming those more direct effects which alone obtain in cold-blooded animals. But under the influence of urari, which paralyses the end-organs of the muscular nerves, a warm-blooded animal behaves as regards its bodily metabolism under the influence of external cold and heat like a cold-blooded animal. "We can best explain these results by supposing that under normal conditions the muscles which, as we have seen, contribute so largely to the total heat of the body are placed, by means of these motor nerves and the central nervous system, in some special connexion with the skin, so that a lowering of the temperature of the skin leads to an increase, while a heightening of the temperature leads to a decrease, of the muscular metabolism. Further, though the matter has not been fully worked out, the centre of this thermo-taxic reflex mechanism appears to be placed above the medulla oblongata, possibly in the region of the pons Varolii. When urari is given the reflex chain is broken at its muscular end, when the spinal cord is divided the break is nearer the centre." 1

How does this bear upon rheumatism? An individual is exposed to a cold draught or gets wet; the surface is chilled; the cutaneous rascular areas are constricted; by reflex action through the vaso-motor system the splanchnic vascular areas and the vessels of the muscular areas are dilated; the vaso-motor nerves distributed to these parts are para-

disc; but no distinct evidence of there having been choked disc or engorged optic nerve, the disturbance not being more than is sometimes found in a high degree of hypermetropia. The defect of vision which he complains of is to be referred to deficient power of accommodation rathe modation is sometimes seen to follow a shock to the nervous system."

2 This patient was seen on April 27 th, and was found to be quite as
modation is sometimes seen to follow a shock to the nervous system." well as at the beginning of the month.

Foster's Physiology, 4 th edition, p. $46 \pi$ lysed, so to speak; with this paralysis of the rasomotor nerves of the parts there is not only a dilatation of the vessels in the part, but there is also a weakening of the power by which the albuminous molecules are held together, and from both causes heat is developed. The normal change of the cyan-alcohols into cyanamides, and amidoacids with the ultimate oxidation of the latter, is modified. The molecules $\mathrm{CH}_{2}\left\{\begin{array}{l}\mathrm{OH} \\ \mathrm{CN}\end{array}\right.$ and $\mathrm{C}_{2} \mathrm{H}_{4}\left\{\begin{array}{l}\mathrm{OH} \\ \mathrm{CN}\end{array}\right.$ become detached from the benzene nucleus, and more or less from each other and by hydration (by which heat is developed) form substances-glycollic acid and lactic acid-which are more easily oxidised than the amido-bodies. The oxygen, though conveyed in larger quantities than normal by the increased blood-supply to the tissue, is completely used up in oxidising the glycollic and lactic acids which have been formed; the excess of lactic acid and the glycocine (which has also been formed) are unoxidised and pass into the circulation. Now, in a normal or healthy state of things, the irritating or stimulating cause acting on the skin being removed, reaction would be set up there, the cutaneous vascular area would dilate, and consequently the vessels of the muscular area would contract, and this latter contraction would be increased by the stimulating effect of the glycocine or resulting uric acid, which, being a morbid product, would stimulate, as in gout, that portion of the nervous system which controls the nutrition of the joints just in the same way as carbonic acid in the blood stimulates the respiratory centre. In this way less blood would go to the muscular area, and the albuminous molecules would again be held more firmly together and undergo the normal changes, the uric acid being meanwhile excreted by the kidneys and the lactic acid by the skin. I have here drawn you a picture of an ordinary feverish cold - the primary chill, the ensuing febrile condition, the elimination of lithates with the subsidence of the attack.

But suppose the individual who is exposed to damp or cold has been previously reduced in strength, is tired out or exhausted - that is to say, his vaso-motor system is in a weak state, the weakness either developed from the above causes, or it may be inherited. Then following the chill there would be the same effects produced as I have above described, but the vaso-motor nerves regulating the vessels of the muscular area would be more completely paralysed, and when reaction set in on the surface of the skin there would be less power in the muscular nerves to recover from that paralysed condition; and more than this, the central portion being exhausted, the stimulus of glycocine or uric acid produces not stimulation, but exhaustion.

Let me illustrate what I mean by reference to the sciatic nerve.

"Division of the sciatic nerve of a mammal causes dilatation of the small arteries of the foot and leg. Where the condition of the circulation can be readily examined, as, for instance, in the hairless balls of the toes, especially when these are not pigmented, the vessels are seen to be dilated and injected, and a chermometer placed between the toes shows a rise of temperature amounting, it may be, to several degrees. ${ }^{2}$ But the dilatation so caused after a few days disappears; the foot on the side on which the nerve was divided becomes not only as cool and pale, but frequently cooler and paler than the foot on the sound side. If the peripheral portion of the divided nerve be stimulated with an interrupted current immediately or very shortly after division, the dilatation due to the division gives place to constriction; the sciatic nerve acts then quite like the cervical sympathetic, except perhaps that this artificial constriction cannot be maintained for so long a time, and is very apt to be followed by increased dilatation. If, however, the stimulation be deferred for some days, until the dilatation has giren place to a returning constriction, the effect is not constriction, but dilatation ; the nerve then acts, so far as its vaso-motor fibres are concerned, like a muscular nerve, and not like the cervical sympathetic. ${ }^{3}$ So also with regard to the mylohyoid muscle. Section of the nerve produces dilatation, but the dilatation is transient. The vessels speedily return to their former calibre, and then it is found that stimulation, of whatever strength, of the peripheral portion of the divided nerve brings about not constriction, but dilatation. If then the vaso-motor fibres of the muscular nerves hare been weakened, the result would be that the normal stimulating effect of uric acid on the motor nerves generally
Ibid., 4th ed., p. 199.
3 Ibid.. p. 209 
would be transformed into a depressing or paralysing effect on the enfeebled nerres, the ressels of the muscular area would be still further dilated, the albuminous molecules would be loosened, hydration and oxidation would go on causing fresh development of heat, there would be the continuous formation of uric acid and lactic acid, the uric acid accumulating in the system, and producing its deleterious effect and modifying the function of the nerrous system; the lactic acid dilating the smaller arteries ${ }^{*}$ and stimulating the sweat centres, passing off in part by the skin. With increased stimulation of the paralysed centre of the muscular nerves complete dilatation of the ressels in the muscular area will take place, the albuminous molecules now fall completely asunder, the $\mathrm{CH}_{2}\left\{\begin{array}{l}\mathrm{OH} \\ \mathrm{CN}\end{array}\right.$ and $\mathrm{C}_{2} \mathrm{H}_{4}\left\{\begin{array}{l}\mathrm{OH} \\ \mathrm{CN}\end{array}\right.$ being entirely hydrated into glycollic acid and lactic acid with the rapid production of heat, and the heat is further developed by the ready oxidation of these products. In this way the so-called hyperpyrexia of rheumatic fever is produced.

But whilst uric acid affects in this way the vaso-motor fibres of muscular nerves, it also affects the nutrition of the joints. We see that in gout; it stimulates and alters the nutrition of the part, and as the blood contains an abnormal substance, this is deposited about the joint in the form of urate of soda. Uric acid increases, too, the oxidation going on in the part, for there is increased heat. These changes are the result of the irritative effect of the uric acid upon the neighbourhood of the medulla oblongata and motor tract. Why I fix upon this as the part specially affected, I will explain presently. But at the age when gout appears, the sympathetic system and the vaso-motor fibres are less susceptible than in former years to irritative causes. Cold applied to the surface of the body in a person of advanced years does not result in increased heat or reaction, but produces internal congestion, pneumonia, hæmaturia, diarrhœea, Sc. In gout the uric acid is the result of modified innervation of the liver, causing a paralysis of the hepatic vessels and lessening of the normal metabolic changes, and so there is non-transformation of the glycocine and the consequent formation of uric acid. In rheumatism the glycocine results from changes in the vascular area and in the metabolism of the muscles, and along with its formation there is also the formation of lactic acid by hydration, both from the cyan-alcohol $\mathrm{CH}_{2} . \mathrm{CH}_{2}\{\mathrm{OH}$ and the cyan-alcohol $\mathrm{CH}_{3} . \mathrm{CH}\left\{\begin{array}{l}\mathrm{OH} \\ \mathrm{CN}\end{array}\right.$; the nutrition of the joint is modified, as in gout, by the stimulating effect of the uric acid on the centre of the muscular nerves, but the nutrition is further modified by the presence of the lactic acid in the blood, producing dilatation of the arterioles, more particularly round the affected parts. For both diseases therefore the treatment resolves itself into neutralising or getting rid of the glycocine, and so prerenting the formation of uric acid and putting a stop to the irritating effect of it on the centre of the muscular nerves. This is effected in large measure by salicylic acid. The glycocine and some portion of the lactic acid in the muscular tissues is derived, as I have shown, from methene cyan-alcohol, $\mathrm{CH}_{2}\left\{\begin{array}{l}\mathrm{OH} \\ \mathrm{CN}\end{array}\right.$. The salicylic acid combines with this as it parts from the albuminous compound forming $\begin{aligned} & \mathrm{CH}_{2} \\ & \mathrm{C}_{6} \mathrm{H}_{4}\end{aligned}\left\{\begin{array}{l}\mathrm{DH} \\ \mathrm{CN} . \mathrm{OH} \text {, which pro- } \\ \mathrm{COOH}\end{array}\right.$ duces no irritating effect on the nerrous centre, and as it passes out of the body is transformed, as is preriously shown, into $\mathrm{CH}_{2}\left(\mathrm{NH}\right.$. $\left.\mathrm{C}_{7} \mathrm{H}_{6} \mathrm{O}_{2}\right) \mathrm{COOH}$, or salicyluric acid.

But along with this remedy the judicious use of cholagogue purgatives will be of great benefit, by eliminating the bile from the intestines, and so removing a quantity of glycocine from the system. And, lastly, the proper diet to employ is one as free from glycocine as possible-that is, one consisting chiefly or entirely of milk and farinaceous food. From what I have said it is also easy to understand how a number of blisters applied near the affected joints may often cure the disease-viz., by reflex action on the vessels of the muscular area, causing them to contract, and so diminishing the metabolism and lessening the formation of glycocine.

A word or two, lastly, with regard of the pathology of that form of diabetes which originates in the muscular tissue. In my previous paper I have indicated the way in which I think it probable that glucose may in the living body be derived from albuminous material-namely, by the separation of the molecules of $\mathrm{CH}_{2}\left\{\begin{array}{l}\mathrm{OH} \\ \mathrm{CS}\end{array}\right.$ from the benzene nucleus, their hydration into glycollic acid, $\mathrm{CH}_{\mathrm{a}}\left\{\begin{array}{l}\mathrm{OH} \\ \mathrm{COOH}\end{array}\right.$, and

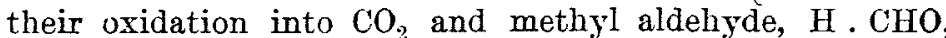
and water; the oxidation being arrested here, and condensation of six molecules of the aldehyde taking place, forming $\mathrm{C}_{6} \mathrm{H}_{10} \mathrm{O}_{6}$, or glucose. Here we have, then, a condition resembling somewhat that associated with hyperpyrexia, except that the oxidation is in some measure inhibited. The vaso-motor fibres of the muscular nerve are paralysed, the molecules $\mathrm{CH}_{2}\left\{\begin{array}{l}\mathrm{OH} \\ \mathrm{CN}\end{array}\right.$ are detached and hydrated, but only partially oxidised; the tissue is, so to speak, partially urarised, the aldehyde is not oxidised, but condenses into glucose. In urari poisoning sugar appears in the urine, though "the exact way in which this form of diabetes is brought about has not yet been clearly made out."

Now, you will find that in some forms of diabetes salicylic acid is of the greatest importance, whereas in others no good results from its use. The urine in the former cases contains often, in addition to glucose, an excess of uric acid, and the patients suffer from neuralgic pains in the joints and limbs. Their diabetes is said to be "gouty"; but it seems to me that the presence of the uric acid and some of the glucose in the urine is due to imperfect metabolism in the muscular tissue, in the manner above indicated.

Gentlemen, I have already trespassed upon your patience too long; 1 will, therefore, only very briefly indicate on what grounds I localise that portion of the nervous system which controls the nutrition of the joints, and the function of which is affected by uric acid, about the medulla oblongata and the motor tract.

1. Rheumatism not infrequently after a short interval follows tonsillitis. Now, we may assume either that the condition of the central nerrous system in the individuals so affected is such that the slight injurious influences acting upon that portion of the central nervous system will produce an attack of quinsy, whereas more severe injurious influences will cause rheumatic ferer; or we may assume that in quinsy the irritation of the nerves distributed to the tonsils not only affects the central nervous system at the origin of the roots of the nerves supplying the irritated part, but through the sympathetic nervous ganglia the irritation radiates to other parts of the nerrous system which are in connexion with that ganglion. Wither hypothesis will answer my purpose. The tonsillar nerves are derived from the fifth nerve-the middle descending branch from Meckel's ganglion-and from the glossopharyngeal portion of the eighth nerve. This branch of the fifth, to which I have referred, is derived from the larger root of the nerre which may be traced back to the lateral tract of the medulla oblongata immediately behind the olivary body, and is connected with the grey nucleus at the back part of the medulla between the fasciculi teretes and the restiform columns. The deep origin of the glosso-pharyngeal may be traced through the fasciculi of the lateral tract to a nucleus of grey matter at the lower part of the floor of the fourth ventricle, external to the fasciculi teretes. Both these nerves receive filaments from the superior cervical ganglion of the sympathetic.

2. In locomotor ataxy, associated with sclerosis of the posterior and lateral columns of the spinal cord, the joint affection known under the name of Charcot's ataxic arthritis sometimes presents itself. At the present moment we have in the hospital here a case of this kind, showing very conclusicely the connexion between swelling of the knee-joint and irritation at the root of the fifth nerve, and in particular of the root of the anterior dental branch.

P. R - , aged fifty-nine, was admitted into Addenbrooke's Hospital Jan. 19th, 188.5. At serenteen years of age he had pleurisy ; during convalescence the right knee began to swell. Four years later the thigh was amputated owing to disease of the knee-joint. For twelve rears after that he had good health, and then was suddenly attacked one night with sharp pain in the stump. In the morning he had neuralgia affecting the middle division of the fifth nerre. This came 
on regularly for eighteen months at 11 A.M., and since then has been very nearly continuous, but with exacerbations. He had ague when thirty-nine years old. At intervals there has been pain in the stump. He has had all his teeth removed from the upper jaw excepting one carious stump, on account of the pain, but without any relief. For the last three years he has noticed that at times he could not pass water, and at others it would run away from him. He has had aching pains in the left tibia for four years, but never had any lightning pains. In August, 1884, he suffered from violent abdominal pain lasting three months, and attended with sickness. He complains now of great pain in the upper gum, and compares it to that produced by a red-hot iron passed along the upper gum from the centre to the back, the attacks coming on at intervals of a few minutes, and lasting about ten seconds. On March 2 nd he complained of numbness in the left leg, pain at the lower end of the femur and outer side of the thigh. There is no patellar reflex, no ankle clonus. The leg and thigh subsequently became pedematous and brawny, the knee-joint became distended and contained fluid, the ligaments very lax, allowing very free lateral movement; no creaking; no bony outgrowth was discovered. As this swelling of the leg and joint developed the pain in the jaw declined. On May 22nd the junctions of the ribs with the costal cartilages became swollen and very tender, and the patient also complained from time to time of aching pains in the shoulders. The joint is less swollen; the ribs are less tender just now. I have referred to the case as a good illustration of what I want to prove-viz., that irritation about the root of the fifth nerve will also sometimes give rise to modifications of nutrition in the ends of the bones or about the joints.

Lastly, with regard to chorea. It is not difficult to see that, if the power of the vaso-motor fibres has been weakened, an irritation at the root of the fifth nerve may by radiating through the Gasserian ganglion or Meckel's ganglion, which are in connexion with the carotid plexus-a superior branch, that is, of the upper cervical ganglion-cause vascular dilatation and perivascular change in the track of the middle cerebral artery, and that these changes would produce the incoördinated movements of chorea. Dr. Dickinson has made out very clearly that it is in these parts and in the posterior and lateral parts of the grey matter and in the upper portions of the cord that vascular dilatation and perivascular change take place both in chorea and diabetes; and $I$ venture to suggest that they are induced in the manner I have indicated.

\section{NOTES OF VISITS TO CONTREXÉVILLE AND ROYAT-LES-BAINS.}

By F. R. CRUISE, M.D. UNIr. DUB., PRESTDENT OF THE KING AND QUEEN'S COLLEGE OF PHYSICIANS IN
IRELAND.

(Concluded from page 11:3.)

BeFORE concluding, I should like to add some notes of a visit which I paid to Royat-les-Bains in June, 1884, and of the circumstances which brought me there.

One day, in the spring of last year, I happened to complain to my friend and colleague, Dr. Patrick Hayes, about the great annoyance I had suffered from eczema. This affection, presumed from many special symptoms to be of a gouty nature, had been treated in various ways, but with very partial success. Dr. Hayes told me that a patient of his, very similarly affected, had been sent by a London physician to Royat-les-Bains, and had been effectually cured. A few inquiries satisfied me that this mineral watering-place enjoyed a well-merited celebrity in the treatment of chronic forms of gout, and I felt that it was well worth my while to pay it a visit. Accordingly to Royat I went in June, 1884, and, to make a long story short, I was cured so completely that with a little attention to diet, and some other hygienic details, I have escaped ever since all annoyance from my troublesome ailment. It is but truthful to add that $I$ have kept up the use of the waters, and observed the rules of life laid down for me. Many patients who are careless about these matters blame very unjustly the remedy which they unreasonably expect will cure them despite of themselves. Anyone who has undergone for years the indescribable worry of eczema will understand that I naturally feel very grateful to Royat, and am anxious to make known to the members of the Academy of Medicine in Ireland some details concerning it.

Leaving Paris by the Lyons Railway, a journey of some nine hours brought me to Clermont-Ferrand, the wealthy capital of the Auvergne district, and in ten minutes more I arrived at the picturesque village of Royatles-Bains, one of the most celebrated mineral stations of France. Once settled in my hotel (Chabassière's), which it is but just to say combined erery comfort with moderate charges, I sought the advice of Dr. Alexandre Petit, whose brochure on Royat I liad already studied. Under his guidance I commenced the course, which lasted three weeks. The routine was much as follows:-At 7 A.M. I took a glass of the Eugénie water hot from the spring, then a reclining bath in the same water at a temperature of $95^{\circ} \mathrm{F}$. After the bath I had another glass of the water. Then I returned to my hotel, and had coffee and strawberries. At one o'clock déjeuner à $l a$ fourchette; at 4 to 5 P.M. two glasses of the St. Mart spring, with fifteen minutes between; at 6 o'clock dinner. Thus I passed the days, spending the leisure intervals in exploring Royat and its environs, and in observing the use and effect of the waters. Day by day $\mathrm{I}$ improved in health and spirits, the eczema cleared off, and no new spots appeared. As already stated, I have remained well now just a year.

Royat-les-Bains is a village, consisting mainly of the établissement for the waters and baths, the hotels, boardinghouses and villas, which accommodate the visitors in the season, from May till the end of September. It is beautifully situated in the Auvergne mountains, about 1500 feet above the sea level, in a valley stretching from the base of the Puy-de-Dôme to Clermont-Ferrand, and following the course of a torrent of lava which at some remote age poured down from the neighbouring rolcanoes, now completely extinct. The lowest portion of this valley conveys the Tiretaine, a mountain stream of some considerable size. All that a lovely country, an agreeable bracing climate, a wealth of interest, historical, geological, and botanical, combined with health-giving waters, can offer to satisfy the visitor will be found in plenty at Royat-les-Bains. To those who love mountain scenery as I do, no day spent there can feel irksome or tedious. It is right to add that it is a very quiet spot, to which the world of fashion has not yet penetrated; but its fame is of old standing, it is thoroughly appreciated by the medical faculty and people of France, and is yearly becoming better known to the world at large.

To prevent confusion about names, let me observe that Royat, the original village, is situated about fifteen minutes walk higher up in the valley than Royat-les-Bains, and, though most interesting to visit, is not the mineral station known as Royat. The original village is evidently of great antiquity, resembling a miniature old Roman town. The photographs which I exhibit, many of which I took myself on the spot, show the curious old streets in which it abounds, and the castellated and battlemented church, a RomanoByzantine edifice, dating from the twelfth century. There are clear evidences that the ancient Romans knew Royat well, and used its hot springs, both for separate baths and for the piscine or general swimming tank. Just below the railway bridge may be seen the remains of Roman baths and piscine, close to the St. Mart Spring, which were discovered in 1843. These are some of the many ruins which prove the Roman occupation of Royat in ancient times. The entire neighbourhood of this station abounds in interesting places, which serve to occupy the leisure hours of visitors to the waters.

Clermont-Ferrand, to which I have already alluded, is a little over a mile from Royat, and may be reached by omnibus in about ten minutes. Expeditions are made thither almost daily, and I know no more agreeable stroll than to wander through its beautiful Gothic cathedral, and then walk down to the Place Pascal, in which we find the statue of the great philosopher, so placed as to look to the distant towering Puy-de-Dôme, upon the heights of which he performed the experiments which led to such advance in barometric science. Selecting a clear day, a journey of some two hours and a half brings to the summit of the Puy, with its ruined Temple of Mercury, now replaced by an observatory, from which a magnificent view of the surrounding country stretches out on all sides. In every direction about Royat we find beautiful mountain passes through which to ride, drive, or walk; picturesque old towns and villages, and ruins of ancient castles 